\title{
Motorcycles, Snails, Latour Criticism without Judgement
}

\section{StePHEN MUECKE}

UNIVERSITY OF NEW SOUTH WALES

\begin{abstract}
I can't help but dream about a kind of criticism that would try not to judge but to bring an oeuvre, a book, a sentence, an idea to life; it would light fires, watch the grass grow, listen to the wind, and catch the sea foam in the breeze and scatter it. It would multiply not judgements but signs of existence; it would summon them, drag them from their sleep. Perhaps it would invent them sometimes-all the better. All the better. Criticism that hands down sentences sends me to sleep; I'd like a criticism of scintillating leaps of the imagination. It would not be sovereign or dressed in red. It would bear the lightning of possible storms.
\end{abstract}

Michel Foucault, 'The Masked Philosopher'1

The multiplication of 'signs of existence'.2 And their invention sometimes. What a challenge! Foucault knew very well that judgement is practised all the time, that it is 'one of the simplest things that mankind has been given to do', yet his gift to us is a dream of some other activity for criticism. He was conscious, as we still are, that the 
practice of the humanities seminar, where students are trained to become certain kinds of subjects, focuses on the refinement of judgement, including the calibration of moral thresholds, the creation of taste, and the development of an ear for tone. If students graduate from that seminar self-confident enough to judge what is true and beautiful, the tutor will have done-no doubt about it—an excellent job.

Now, over twenty years later, Bruno Latour comes along with his criticism of critique. His 'tone' is satirical, and his method ethnographic as he describes what happens in the very graduate school that delivers the kinds of critical moves needed for judging truth and beauty:

Enter here, you poor folks. After arduous years of reading turgid prose, you will be always right, you will never be taken in any more; no one, no matter how powerful, will be able to accuse you of naïvité, that supreme sin, any longer? Better equipped than Zeus himself you rule alone, striking from above with the salvo of antifetishism in one hand and the solid causality of objectivity in the other. The only loser is the naïve believer, the great unwashed, always caught off balance. Is it so surprising, after all, that with such positions given to the object, the humanities have lost the hearts of their fellow citizens, that they had to retreat year after year, entrenching themselves always further in the narrow barracks left to them by more and more stingy deans? The Zeus of Critique rules absolutely, to be sure, but over a desert. ${ }^{3}$

Both French writers owe something to Nietzsche, and indeed Antonin Artaud, in their elaborations of the violence of judgement and the arrogant righteousness of critique, coupled with a sneering disdain for mere facts. The genealogy of critical judgment can also be traced to the university model established by Emmanuel Kant in early modern Europe when certain core values could still be fairly confidently asserted. ${ }^{4}$ Today, that Kantian Christian transcendentalism is no longer centre stage in a multicultural world where few such core values can be taken for granted, but must be negotiated, even in the micropolitics of the classroom.

Rather than continue the criticism of critique directly, I will pursue instead an experiment with the experimental, an alternative thread in continental philosophy which seeks to provide (hopefully) a more realistic vision of collective assemblages of life-forms, where the human (paradoxically for the humanities) finds itself less 
centred. It emerges from its roots in Spinoza, Bergson and Diderot, continues via Deleuze and Guattari, then William James and A.N. Whitehead, who have been revived in recent years.

What do I mean by 'experiment'? I define the concept in two ways, first by contrasting it to the practice of judgement in the writing of the kind of prose we call criticism. Experimental writing, for me, would be writing that necessarily participates in worlds rather than a writing constituted as a report on realities seen from the other side of an illusory gap of representation. Judgement is enabled by such gaps, and we give them names like 'critical distance', 'omniscient overview', 'hindsight' or 'perspective'. ${ }^{5}$ Knowing that forms of judgment are unavoidable, the move to the experimental attitude involves reflecting on the formation of such critical subjectivities. How does critical prose, of the kind that would judge, earn the right to its 'critical distance'? By what steps does one get to this position of critique? By contrast, the experimental alternative is contingent and negotiable and prefers to ask how one earns the right to participate in the event-the seminar, the colloquium, the multidisciplinary research project.

It should be clear that the experimental writing I envisage is not about breaking free of convention, but is actively engaged in creating assemblages or compositions as it goes along. This engagement may be with different registers of reality, because 'the world' is not seen as bifurcated, with the 'text' mediating the 'subject' and the 'object', as in older communication models. ${ }^{6}$ In this multirealist environment, writing cannot elevate the subject to a transcendent/romantic position, where human imagination 'creates worlds' so as to redeem a lost plenitude. Because of its constant imbrications or engagements, it seems to make more sense to support it with an immanent/vitalist conceptual architecture. John Rajchman's position on Deleuzian philosophy summarises this difference, characterising Deleuze's radical empiricism as an 'empiricism that tries to push beyond judgment to an invention and an affirmation that precedes it-to that point where experimentation in philosophy becomes inseparable from vitalism'. ${ }^{7}$

So I am catching on to the vitalist thread in contemporary philosophical thought from Bergson to the post-Deleuzians. And in the other hand I am holding a thread from Indigenous Australian thought, also vitalist, which taught me about 'keeping things alive in their place' to create a slogan. ${ }^{8}$ I want to see what these two 
threads can do for a writing practice and even a literary theory that are localised, rather than universal in aspiration. They constitute events performed in particular places.

I speak of 'keeping things alive in their place' because it encapsulates what I have learned from Aboriginal elders in Australia about the maintenance of cultures; authors like Paddy Roe, David Mowaljarlai and David Unaipon. ${ }^{9}$ For them, singing, dancing, writing, or other forms of performance, are not communicative items created for distribution. They are more like ecological events, existing more spatially than temporally; they have their roots in sacred country. And there are protocols of participation: who is the 'boss' for this particular performance, and how are rights to participation earned? Who can watch and listen? How are non-human things earning their rights to participate? Plants, animals and waterholes, but also other registers of reality like spirits, dreams and fictional beings. 'Keeping things alive in their place' is an a-modern vision. For if a modern genre like the detective story can become popular and spread around the world thanks to the machinery of mechanical reproduction and reproductive machinery of capitalist organisation, that is one kind of networking that certainly functions well, but transcends specific places. If one is more interested in cultural forms that have local coordinates, one might see them with their tendrils embedded ecologically, like roots from a seed. Does a seed have imperial ambitions, like the modernist commodity? Certainly, and weeds will take over the garden in their own unique ways of moving through their world. But they are limited by their resources, including the humans who chose what kind of culture they want to nurture.

A second aspect of my experimental attitude involves speculation, and for me that means asking about the reality of the relations between things, relations that are not dominated by the human experience of those things. ${ }^{10}$ That is a hard task, for how do you imagine the relation between a snail and the leaf it is eating (which is perfectly real as a relation) without anthropocentrism, without scientific reductionism, even without language? That's one problem, especially pertinent for the field of ecological writing, conceived of as non-human centred (and therefore giving agency to non-humans), empirical, and engaged in that contingent on-going fashion described above. 
The sign says: In my world home loans are flexible. Catching a glimpse of the Citibank advertisement as I zip by. The guy looks, well, relaxed. 'My world', on the other hand is in movement. I am riding a kind of work of art, a Kawasaki W650 recreated as a café racer by the Deus Ex Machina design concept workshop in Camperdown. A beautiful engine in the British twin style, but with the bevelled gear driving the overhead cam. It's all silver and black; Daytona headlight and speedo, Nitrohead seat and Deus custom P-Nut aluminium tank. The speedo seems to read 10 per cent too slow. The tuned length 'Up 'n' Over' scrambler pipes burble happily at low revs and 'play Mantovani over 3000rpm', as the writer down at Deus says. As rider, I could say that my 'judgement' in taking corners is 'critical', just to remind us of another way these words slumber in everyday usage.

Is that all? No, my world is also something much more ancient and equally subtle. It is a machine-human assemblage where the machine itself, to be straddled by one or two people for rapid movement, seems to derive some of its form or capacities from the horse. Yet this assemblage is based also on the ancient invention of the wheel, not only the two large ones, but the constellation of cogs and gears that play their own versions of Mantovani in the drive train. And the even more ancient material of its power, derived as it is from a refined essence of decayed and liquefied carboniferous rain forests from a much, much older world.

A leaf fell from a dinosaur's mouth into the river and that was the carbon in the explosion in the left cylinder of the W650 just now, just perhaps. There are pathways crisscrossing time and space from the ancient to the modern, making multiple pleats of time in the present, and I won't go into any detail about the pathway of the evolution of the internal combustion engine, going back, the myth says, to James Watt sitting in his mother's kitchen and noticing the rattle of the lid of the kettle. A transfer of vitality, but from what to what? Watt to whom? The prototype steam engine has power, so does Watt's imagination, if you are asking yourself: where does the power of steam come from, if you really want to trace it back? Then you can never be sure about the boundaries of material life. Doesn't Mrs Watt's mythical kettle also embody something imaginative to do with its initial creation and then its creative evolution? Don't we then have to conceive of humans, 
non-humans and things as equally active agents operating on different registers? Could it be our task to describe the mediations?

This is my world. Not the world of the guy whose happiness is flexible interest rates, or the other Citibank woman who says her world is a credit card that rewards her-and she has bright red shoes to prove it. Is my world the world of riding a motorcycle to work? Not really. If I have just demonstrated anything, it is that mine is a world of words, words that have this capacity to create pathways among different kinds of reality. Words, not language. Language, conceived of as 'finding its conditions of possibility ... in the purely apositive relations of the language system or code',11 is of no interest, but words have historical contingencies, and therefore capacities to jerk us around, surprise us as we wake up to some other kind of existence staring us in the face. Walter Benjamin spoke of 'the tiny spark of contingency', of the 'here and now', in a photograph, 'with which reality has ... seared the subject'.12 Likewise, etymological tracings are unique pathways zig-zagging across worlds, as in this elaboration of the word 'world' itself: the English word 'world' comes from the Old English weorold (-uld), a compound of wer 'man' and eld 'age.' Wer, as in were-wolf. World thus means roughly 'Age of Man'. The corresponding word in Latin is mundus, literally 'clean, elegant', itself a loan translation of Greek cosmos 'orderly arrangement'. While the Germanic word thus reflects a mythological notion of a 'domain of Man', presumably as opposed to the divine sphere on the one hand and the chthonic sphere of the underworld on the other, the Greco-Latin term expresses a notion of creation as an act of establishing order out of chaos. ${ }^{13}$

\section{-MULTIREALISM}

Unique pathways in and among the multiply-real, then. I have read snippets about Bruno Latour's forthcoming huge metaphysical tome, On the Different Modes of Existence, which finds him completely by-passing humanist phenomenology. Latour has wicked little digs at the phenomenological orthodoxy, caricaturing it as so metaphysically challenged that most philosophers don't even need the fingers of one hand to be able to count the number of possible ways of 'being in the world'. They recognise only two, the objective and the subjective. Everything they encounter is heading either to the status of the solid brick or towards that of ineffable human 
consciousness. But despite that, they love to announce that there is a 'beyond subject and object', or a 'beyond nature and culture'. So they arrive at finger number three, but have no idea what they are counting on it. ${ }^{14}$

In Latour's more ecological multirealist philosophy, things can exist without being a function of the way humans look at the world, as it everything hung off that relationship. The Copernican revolution may be over, when God was scientifically dethroned and Man became central, giving rise via the Enlightenment to the last few hundred years of secular humanism. Latour's idea of admitting all sorts of 'beings' as actors is central to this new multirealism: an apple can be an actor, as can a breath of wind, a concept such as happiness or a person. Then they gather to form hybrid alliances, as in the way our domestic households function as a shifting set of alliances of humans, plants, animals and inanimate objects, forming relations all the time.

In Latour's philosophy each actor is respectfully admitted into a democracy of such relations. One tries not to reduce one thing to being the effect of something else, in the manner that a sociology can reduce a religious experience to a set of structures and functions, or a religion can reduce AIDS-preventing condoms to a sin against human fertility. These sorts of reductions can, and are, made, more or less convincingly, but only through a series of hard-won negotiations and transformations from one link to another in a network of associations.

Politics, unsurprisingly, lies in the relative strength or weakness of such alliances. If you want to prove that the earth moves around the sun, you'd better gather allies to your cause (telescopes, rational calculations, diagrams and influential friends and patrons) before the Inquisition, with the help of its allies, burns you at the stake. But from a philosophical point of view, the principle of 'irreduction', as Latour calls it, introduces politeness into the discussion for the first time in centuries, as Latour's 'multi-naturalism' urges us to respect different modes of existence.

So Latour has to take off one sock to count his modes of existence; there may be up to fourteen in various combinations in his system. If you are used to philosophers thumping on tables or pointing at glasses of water when they want to evoke the real, then this can no longer happen with him. There are no primary, more solid realties followed up by secondary effects like subtle feelings or meanings. Rather, everything 
is real, and it is approached with a rigorously empirical and experimental attitude. This means that everything is a work in progress as a negotiable alliance of things. A religious ceremony can attain its desired reality as a mode of religious existence through the alliance of all that is needed: a congregation and a representative of God, sacred words, artefacts and icons, music, the smell of incense. It is a work in progress because of the on-going effort; if its reality were given in advance it would reduce to dogma and have the same kind of existence as other forms of dogma.

Since the Enlightenment, humans have stopped seeing themselves as God's pale creatures, and became central to their own thought. But in Latour's scheme the human has no special mode of existence, and so in this it differs markedly from humanist philosophies that work so hard at maintaining the human/non-human divide. In his political ecology, humans are not central. We are, after all, only a couple of chromosomes away from chimpanzees. But living things as a whole class reproduce, so reproduction is one of his many modes of existence, and I want to link it to vitality a bit later on. 15

\section{-OBJECT-ORIENTED WRITING}

It seems too naïve to ask, but how do you break out of the formula: 'I am interpreting the world'? We might assert two things first of all as premises: 1) there is no line of communication between subject and object; and 2) along that fictional line between subject and objects there would be no gaps, metaphysical voids or inbetween spaces to get lyrical about. The conceptual image a lot of us share now is more along the lines of a network of shifting relations sustaining a range of delicate existences. So then we might experiment in this direction with something I am calling object-oriented writing, ${ }^{16}$ for which the slogan is, 'let the object talk to the writing'-without worrying too much about defining the object, this move in the experiment is heuristic-it is about respecting the strangeness, as anthropologist Mick Taussig says:

It is more like having the reality depicted turn back on the writing, rather than on the writer, and ask for a fair shake. 'What have you learned?' the reality asks of the writing. 'What remains as an excess that can't be assimilated and what are you going to do with the gift that I bestow, I who am such strange stuff?'17 
In Creative Evolution, Bergson says: 'The idea that for a new object we might have to create a new concept, perhaps a new method of thinking, is deeply repugnant to us.' 18 This is because we have our carefully constructed macro systems, deduced from describable micro elements. But the 'strange stuff' talking to the writing; this is suggesting to me a slogan like respect the signature of the thing (a wonderful object will feel let down if you write something boring about it, something that reduces it to macro principles (Newton's laws of motion), or gets lost in the micro detail (it is largely made up of carbon atoms). Isabelle Stengers offers a way out with what she calls the meso level. She might ask: What is the character of the motorcycle? What makes the tyres stick to the road as it leans fast into a corner? There are (macro) Newtonian answers, just as there are (micro) answers about the temperature of rubber molecules. But the meso level is what the head Kawasaki mechanic knows about a certain race-bred model and how it will respond at the Phillip Island track in the rain. It is the mechanic's feeling for the character of the machine that the driver trusts when he switches tyres. It's all about keeping things alive in particular places.

\section{-WHAT? THINGS ARE ALIVE?}

Not just keeping the motorcycle racer alive, but possibly the culture of motorcycle sports which depends on a whole bunch of affective relations. The love of the thing. Multiple connections enhance the life of the machine; it is a complex object which, like anything that is not an atom, is composed, and keeps on being composed, built on, by those who participate in its life. So now, with the help of Bruno Latour, I want to think about objects like motorcycles (or humans or snails) as animated in their multiple connections, carefully forged and nurtured, rather than following the materialist orthodoxy:

One of the principal causes of the scorn poured by the Moderns on the sixteenth century is that those poor archaic folks, who had the misfortune of living on the wrong side of the 'epistemological break', believed in a world animated by all sorts of entities and forces instead of believing, like any rational person, in an inanimate matter producing its effects only through the power of its causes... 
This conceit has the strange result of composing the world with long concatenations of causes and effects where (this is what is so odd) nothing is supposed to happen, except, probably at the beginning-but since there is no God in those staunchly secular versions, there is not even a beginning ... The disappearance of agency in the so called 'materialist world view' is a stunning invention especially since it is contradicted every step of the way by the odd resistance of reality: every consequence adds slightly to the cause. Thus, it has to have some sort of agency. ${ }^{19}$

So what is the consequence of this animist attitude that runs the risk of sounding New Age-ish? It makes me write differently for a start. I approach the machine bearing the name of god with trepidation and with affection. In the background is a memory, from years ago, of bringing home a Velocette MAC350. I started it up and it roared into life. But the carburettor was jammed. I tried to shut it down by putting it into gear, but it went wild in the garden, churning up my mother's asparagus patch, before I finally subdued it. Today the life of the Deus depends in part on another woman, my partner Patience, who says, 'I'm telling you now, I'll not be visiting you in hospital, so take care.' The object engenders life, like a pebble always creating ripples in its place, spreading out and engaging other beings and other worlds. Its life also depends on the kind of mythology it carries, its deep historical meanings that in turn engender affect and sense. What kinds of human dreams are there in the story, composing all this material into wondrous speeding contrivances?

So the animist attitude is compositionist to the extent that it acknowledges the agency of all the elements of the composition. Yet our secular materialism tells us that we can't mix dreams with memories, with speculations about the origins of petrol in pre-historic rainforests. It urges us to treat things as if they were all dead. This is the same materialism that tries to maintain a strict ranking of importance of actors in a reality as complex and as interrelated as 'the economy'. For which, the 'bottom line' is, what? Exchange value? Resource wealth? In relation to that mightily powerful set of stories and rituals we call the Economy, we also have to bring 'trust', 'investor confidence', fantastic arrays of numbers, not to mention a certain type of office décor, suit and haircut to inspire that same 'investor confidence'. Then there is 
an advertising campaign to mobilise our desires for home, as Citibank urges us to take out a flexible loan, and forget the sub-prime catastrophe.

It is taking up a multirealist embrace that is the issue here. For us humans that means writing the multirealist experience, something we who have 'been there' can try to report on even as we create it. Our reports 'from the field' try not to be reductions to one level of reality (the experience of the motorcycle reduced to the signs and functions of the strictly materialist language of, say, mechanical engineering or of sociology; that is, a purely referential language), but reports that envelop the poetry, the sensorium, the history, the mythology and the politics. The whole damn culture in other words.

What kind of energy does this culturally composed world run on, for it is not the machine of knowledge accumulation, or the combustion engine of critique (which Latour famously described as 'running out of steam'). In the humanities, critique is the engine of debunking, revealing, or unmasking the reality that lies behind mere appearances:

Critique, in other words, has all the limits of utopia: it relies on the certainty of the world beyond this word. By contrast, for composition, there is no world of beyond. It is all about immanence.

The difference is not moot, because what can be critiqued cannot be composed. It is really a mundane question of having the right tools for the right job. With a hammer (or a sledge hammer) in hand you can do a lot of things: break down walls, destroy idols, ridicule prejudices, but not repair, take care, assemble, reassemble, stitch together. It is no more possible to compose with the paraphernalia of critique than it is to cook with a seesaw. ${ }^{20}$

So what will keep the compositional machine going? This writing machine that is neither interpreting the world nor denouncing its false appearances? What will give life to words? The same thing, I argue, that gives life to other things; the capacity to reproduce, reproduce, that is, with carefully chosen partners.

\section{-RePRODUCTION AND READING}

In 1979, literary and cultural theorist Tony Bennett had the insight that if 'production is completed only with consumption, then, so far as literary texts are 
concerned, their production is never completed. They are endlessly re-produced, endlessly remade with different political consequences and effects.' 21 To this important insight about intertextual effects, we can attempt to flesh out the multimodal or multirealist networks that intersect in a writing or reading event in order to ask how the literary text is keeping itself alive in its place(s), how it is reproducing itself and its culture. Latour insists that there are ontologically different modes of existence involved in any event. 'Reference' is about the chains along which knowledge is transferred, whereas 'reproduction' is about something else: the world of 'matter', [Nature] is made of at least two entirely different layers of meaning: one consists of the ways in which reference chains need to be arrayed so as to work, by giving us knowledge of far away entities and processes of all kinds; but the other is provided by a completely different kind of mode, and that is the ways in which the entities themselves manage to stay in existence. Having called the first reference, I will call this second reproduction ... These two contrasts, or to call them by a more ontological term, these two modes of existence, have been constantly confused by modernism, but this confusion does not need to continue with ecology. ${ }^{22}$

Unlike motorcycles, reproduction tends to go at a snail's pace, depending on, I guess, what the speedo is connected to. In 'The Snail Watcher', a short story by Patricia Highsmith, a bunch of snails get seriously out of control.23 This is how the story goes: One evening in his kitchen, Peter Knoppert, mild-mannered stockbroker, is observing some snails in a bowl. They are destined for the dinner table, but he is drawn further into observation, and then fascination, as he attends to the languid lovemaking of a pair of snails. (These hermaphroditic creatures reproduce by inseminating each other over a period of two to twelve hours). Knoppert loses his appetite, gains another, becomes obsessed with his snails; he saves them from the pot and takes them to his library, where he is delighted by their prolific fertility. He does research in the local library, where he finds:

a sentence from Darwin's Origin of Species ... the sentence was in French, a language Mr. Knoppert did not know, but the word sensualité made him tense like a bloodhound that has suddenly found its scent ... snails 
manifested a sensuality in their mating that was not to be found elsewhere

in the animal kingdom. (5)

This key word sensuality drives not only a story but also a kind of contemporary cultural theory, embracing affect. How could we not say that the perceived 'sensuality' of snails is worthy of knowledge and respect? That it reproduces knowledge and respect? Otherwise we reduce the life of snails to the language of reference, where only object-relations can move them, and move their relations to us.

By now there are hundreds of snails in his room at home, he disappears of an evening to be with them. His wife is concerned with this obsession, but it seems to make him happy, even at work:

His colleagues in the brokerage office noticed a new zest for life in Peter Knoppert. He became more daring in his moves, more brilliant in his calculations, became in fact a little vicious in his schemes, but he brought money in for his company. By unanimous vote his basic salary was raised from forty to sixty thousand dollars per year. When anyone congratulated him on his achievements, Mr. Knoppert gave all the credit to his snails and the beneficial relaxation he derived from watching them. (7)

But the fertility of the snails becomes heavy and sinister, leading to the death of Knoppert. As he succumbs beneath the weight of snails in his room, he sees a pot plant, 'A pair of snails were quietly making love in it. And right beside them, tiny snails as pure as dewdrops were emerging from a pit like an infinite army into their widening world.' (10) And that is the end of the story.

My story is a summary of a piece of literature, and of course it illustrates my reproduction theme. I want to argue that literary works reproduce like snails, like living things, given the right conditions. They have to be provided with a culture, which includes a certain devotion, like Knoppert's devotion to his snails. This will involve conceiving literature as something that is always in the process of being made and thus can fail to be made, to be 'instaured', a curious word that Bruno Latour and Isabelle Stengers found in Etienne Souriau. Stengers says, 'I like Etienne Souriau's concept of "instauration" (establishment, institution) very much because, as regards the artist at work, it deploys a quite fabulous assemblage denying any 
power to the old conflict between determination and freedom'.24 But what does she mean by that?

Patricia Highsmith, in a literary experiment, created a character whose devotion to snails changed the form of his life, and theirs. He became more than human and gained vitality; they became more than snail and more sinister. These fictional beings cross two distinct modes of existence, the fictional and the reproductive. Strange, isn't it, that characters in novels are rarely talked about as being 'fictional beings', as if their existence were created and maintained in a genuine ontological difference. More often, critics labour to link them to contexts, to real human beings they are 'loosely based on' vaguely 'reflecting' and so on, all because of the poverty of the subject-object polarity (the two concepts like hooks, Latour jokes, to suspend the hammock destined for philosophical snoozing.) ${ }^{25} \mathrm{~A}$ special kind of existence has to be coaxed into being by writers of fiction; it doesn't arrive without considerable labour. Likewise with the readers. They approach fictional beings with enough devotion to sustain the latters' existence. What is going on in this complex web, creating and maintaining the delicate existence of fictional beings? Characters like Madame Bovary or Mickey Mouse, immortal beings, or a person like the US president, who starts off as a being with a reproductive existence, then as he becomes an object of knowledge, a referential existence, then finally he acquires a fictional existence as well, once the myth-making work is done to invent him as a character.

The work of art is mechanically reproduced, as we know, but so too must be the vitality that sustains the immortal beings who hover around the page of fiction. While a literary text, as an object, is not 'alive', its existence is defined through its active relations with other things, human and non-human, in a complex ecology. The capacity of a writing to 'live' is neither engendered by the life of the writer, nor by any felicitous fit that the writing, as representation, may have with a world. Neither freedom nor determination, as I think Stengers was saying. It is through its capacity to form new relations: writing with rather than writing about. Writing down words in such a way that they 'enter into new partnerships', as they say. Peter Knoppert's snail-becoming is a successful inter-species literary experiment that needs just this singular character to manifest itself in its sudden accomplishment. It is something that a piece of straight prose, a 'report to the academy', cannot do, because it exists 
only in a referential existential register, rather than a reproductive one. Now the generic seed is sown, you too can create another Knoppert character, this time with, say, dragonflies.

Now what does the reader do to help sustain this literary life? In reading a text they create their own instaurations, by bringing characters 'to life' for instance. This ancient Leavisite category of Life can be revived and retheorised. It will not be a question of applying a reductive reading, a Marxist reading or reading 'with Butler' as students are wont to say. These are class exercises, not the kind of regular everyday imaginative readings that read Blake as Blake, if you like, without being drowned out by Marx's voice. My analytic method will now ask two questions of the text: How is it keeping itself alive in its place? (I am refusing there the modernist universalisms that suggest works of art are ungrounded, that they 'transcend' time and place.) And the second question I ask is: What are its partners for reproductive purposes? At this point 'the Marxist reading' can be brought back as a partnership, not as a reduction. Or the offer to read 'with Butler' is an invitation to go on a date: I can't take this story out clubbing just by myself, I need another highly desirable partner as well. Two things then: place-based devotion or cultivation, and no reproduction without getting partners to come to the party. And of course in the ecology of the literary event there are all sorts of partnerships: a comfortable armchair, Coleridge's tranquility, not to mention knowledge and training in certain sorts of affect acquisition. Or in the college ecology, literary events have a different mix sustaining the literary life. 26

The critical prose I have 'reproduced' about 'The Snail Watcher' attempts to retain the multidimensionality of fiction by animating Highsmith's story (as object) into a system of reproduction that can be generalised across various ecologies, including the events of dissemination and teaching. It holds back from judgement as a sovereign capacity (the always threatening, arbitrary and sudden 'judgement of God'). It would prefer, without yet fully realising it, a sustained argument or negotiation that gathers allies (co-workers) around a 'matter of concern' in order to build something, to compose a text, or a corpus of texts. Additional questions for this matter of concern would include: what makes the literary text multirealist? How powerful is (the imagination of) non-human agency in such texts? 
If there is to be a criticism without judgement, then it should avoid that transcendentalism that insists on the incompleteness of the text, its paradoxes and ambivalences so that only in the transcendental move (demonstrated as an intellectual striving by the student) can an elusive infinite unity be glimpsed for a brief rewarding moment. Rather, the radically empirical procedure simply provides formulae for composition within a historically and empirically given tradition, with which the student can experiment to see if they work.

Criticism in this context is not (of course) 'saying what is wrong with things', or in a more sophisticated fashion calibrating moral thresholds, classifying and judging, and setting 'standards'. It is not about cultivating openness (or celebrating gaps and indeterminacies). It is, on the contrary, about real relations (which may be speculative), and robust pragmatic connections across an array of different modes of existence.

Many of these critical reformulations derive from Ian Hunter's work, which to some may look like he is supporting the status quo by failing to accede to the dialectic of history ${ }^{27}$ and thus welcome 'breakthrough phenomena'. ${ }^{28}$ In fact he argues that newness is more likely to come into the world through 'protracted handto-hand intellectual battles'29 than it is by cultivating an intellectual persona who performs the rhetoric of an openness to novelties which are more likely to be metaphysically infinite than specific.

\section{—CRITICISM WITHOUT JUDGEMENT}

Having made this excursion via literary theory to recover the concept of Life, barely, I want to finish with a couple of reflections on making a genre like fictocriticism do the experimental and compositional work I have outlined. What can fictocritical writing do that regular essays or stories can't? Unlike the critical piece, it forestalls judgement in the necessary temporality of its performance. Unlike the short story, its 'problem' is external to it: something comes from outside the literary field and disrupts the usual pattern for the genre. An example: an archeologist friend, Denis Byrne, living in Bali and disturbed by not being able to find objective evidence about the 1965 massacres anywhere on the island, starts to dig for layers of affect in his negotiations with people and things, and these find their writerly correlates in 'Traces of '65: Sites and Memories of the Post-Coup Killings in Bali', ${ }^{30}$ so his new 
affective material changes his writing to the point where the objective is no longer self-evident and has to be speculated about, yet still quite realistically. ${ }^{31}$ It is a writing constantly partnered by what is at stake for my friend: the political pressure of the ghosts of the dead haunting the text, and thus haunting the discipline of archeology.

Interruptions from outside the given discipline or field, then, are the taps on the shoulder that force the writing to write with new partners. I'm not sure if I can claim that this willingness to form new and often unlikely partnerships makes fictocriticism a lively genre, perhaps merely mischievous. I think it offers a way out of that familiar conceptual architecture that has had us 'interpreting the world' and building up critical authority in the process. Now we negotiate, more politely perhaps, with stakeholders in matters of concern, some of whom are non-human. Our literary events are just that, rather than items of communication, and they have to be performed in the writing and in the reading. And if they have a life, it is not a life that they have on their own.

The first great Aboriginal writer and scholar, David Unaipon, wrote something back in the 1920 s that I will ponder forever. He was talking about a certain green frog and how its life depended on the Water Spirit: 'Everything that exists has some life apart from itself', he said. And this Water Spirit, he added, is 'the most multiple spirit of all'.32 Of course it is, it has all these lives to sustain in their places, and these existences include beings constituted in dreams, plants, animals, humans and their different cultures. The real challenge for making genres, I think, will be just how to use writing to trace pathways among multiple realities that affirm their own separate, but mutually sustaining, existences. To do this one must experiment, speculate with new relations among things, and earn participation before judging. When writing moves against alterity, creating the friction and heat of work, it rarely finds a liberation from constraint, as if the experiment would 'open up new spaces' as critical utopianism would have it. Rather, I think, experiments are the transfer of a technology, like writing, to worlds which may not even have writing, and where the protocols are strange and compelling. 
Stephen Muecke is Professor of Writing at the University of New South Wales, Australia. Recent related publications include 'Cultural Science? The Ecological Critique of Modernity and the Conceptual Habitat of the Humanities' in Cultural Studies, May 2009, and 'The Writing Laboratory: Political Ecology, Labour, Experiment' in Angelaki, vol. 14, no. 2, 2009.

-NOTES

${ }^{1}$ Michel Foucault, [1980]. 'The Masked Philosopher' in J. Faubion (ed.), Ethics: Subjectivity and Truth. The Essential Works of Michel Foucault 1954-1984, Volume One, trans. Robert Hurley and others. Penguin, Harmondsworth, Middlesex, 1997, pp. 321-8.

2 Thanks to Noel King for finding the Foucault quotation, to the Cultural Studies Review's insightful readers and to Lauren Berlant and the 'Worlding, Writing' roundtable on making new genres in Chicago in May 2010, which gave some of these ideas a reproductive context.

3Bruno Latour, 'Why Has Critique Run out of Steam? From Matters of Fact to Matters of Concern,' Critical Inquiry, no. 30, 2004, p. 239.

${ }^{4}$ Ian Hunter, 'The History of Theory', Critical Inquiry, no. 33, 2006, pp. 78-112.

${ }^{5}$ On 'critical proximity' see Meaghan Morris, Identity Anecdotes: Translation and Media Culture, Sage, London, 2006 and uptakes by Katrina Schlunke, 'Captain Cook Chased a Chook', Cultural Studies Review, vol. 14, no. 1, 2008, pp. 43-54 and Jane Simon, 'Critical Proximity', Cultural Studies Review, vol. 16, no. 2, 2010, pp. 4-23.

${ }^{6}$ Stephen Muecke, 'Public Thinking, Public Feeling: Research Tools for Creative Writing', TEXT, vol. 14, no. $1,2010<$ http://www.textjournal.com.au/>.

${ }^{7}$ John Rajchman, 'Experiment' in The Deleuze Connections, MIT Press, Cambridge, Mass., 2000, p. 27.

${ }^{8}$ Stephen Muecke, Ancient and Modern: Time, Culture and Indigenous Philosophy, University of NSW Press, Sydney, 2004, p. 34.

${ }^{9}$ Krim Benterrak, Stephen Muecke and Paddy Roe, Reading the Country: Introduction to Nomadology, University of Liverpool Press, Liverpool, 1996; David Mowaljarlai, with Jutta Malnic, Yorro Yorro: Everything Standing up Alive: Spirit of the Kimberley, Magabala Books, Broome, WA, 1993; David Unaipon, Legendary Tales of the Australian Aborigines, Melbourne University Press, Melbourne, 2001.

10 The critique of 'correlationism' as a dominant form of humanist phenomenology can be found in Quentin Meillassoux, After Finitude: An Essay on the Necessity of Contingency, Continuum, London, 2008. For a related discussion of speculative realism, see the journal Collapse, vol. 3, ed. Robin Mackay, Urbanomic, Falmouth, 2007, and Graham Harman, Towards Speculative Realism: Essays and Lectures, Zero Books, Ropley, 2010. 
${ }^{11}$ Ian Hunter, p. 91.

${ }^{12}$ Walter Benjamin, 'A Small History of Photography', One Way Street and Other Writings, trans.

Edmund Jephcott and Kingsley Shorter, London, [1931] 1979, p. 243.

${ }^{13}$ Adapted from the $O E D$ entry.

${ }^{14}$ Bruno Latour, 'Reflections on Etienne Souriau's Les différents modes d'existence', trans. S. Muecke, in Graham Harman, Levi Bryant and Nick Srnicek (eds), The Speculative Turn, re.press, Melbourne, 2011, pp. 304-33.

${ }^{15}$ Much of this section is adapted from my own 'Beyond The Eye of the Beholder', review of Graham Harman, Prince of Networks, Australian Literary Review, 3 March 2010, pp. 6-7.

${ }^{16}$ See also Graham Harman's 'object-oriented philosophy' in the publications cited.

${ }^{17}$ Michael Taussig, Walter Benjamin's Grave, Chicago University Press, Chicago, 2006, pp. vii-viii.

${ }^{18}$ Bergson, Creative Evolution [1913], quoted in Claire Colebrook, Deleuze and the Meaning of Life, Continuum, London, 2010, p. 2.

${ }^{19}$ Bruno Latour, 'An Attempt at Writing a “Compositionist Manifesto"', New Literary History, no. 41, 2010, pp. 471-90, 481-2.

20 Ibid., p. 475

${ }^{21}$ Tony Bennett, Formalism and Marxism, Methuen, London, 1979, p. 136. My emphasis. Thanks to John Frow for reminding me of this quotation.

${ }^{22}$ Bruno Latour, 'Will Non-Humans be Saved? An Argument on Ecotheology', Journal of the Royal Anthropological Institute, no. 15, 2009, pp. 459-75, 466.

${ }^{23}$ Patricia Highsmith, 'The Snail Watcher,' in Patricia Highsmith, Eleven, Heinemann, London, 1970, pp. 1-10. Further references are included in the text.

24 'History through the Middle: Between Macro and Mesopolitics, Interview with Isabelle Stengers', Inflexions, no. 3, <http://www.senselab.ca/inflexions/volume_3/node_i3/stengers_en_inflexions_vol03.html>.

${ }^{25}$ Latour, 'Reflections on Etienne Souriau', p. 309.

${ }^{26}$ Stephen Muecke, 'The Writing Laboratory: Political Ecology, Labour, Experiment', Angelaki, vol. 14, no. 2, 2009, pp. 15-20.

${ }^{27}$ Fredric Jameson, 'How Not to Historicize Theory', Critical Inquiry, vol. 34, no. 3, 2008, pp. 563-82.

${ }^{28}$ Hunter, p. 81.

${ }^{29}$ Hunter, p. 103.

30 Denis Byrne, 'Traces of '65: Sites and Memories of the Post-Coup Killings in Bali', UTS Review, vol. 5, no. 1, 1999, pp. 37-52.

31 'Speculative realism' means 'a realism dedicated to overthrowing the prejudices of common sense.' Graham Harman, personal communication, Tuesday 8 March 2011.

32 Unaipon, p. 53. 